Int. J. Dev. Biol. 50: 27-37 (2006)

doi: $10.1387 / \mathrm{ijdb} .052107 \mathrm{~cd}$

Original Article

\title{
Common culture conditions for maintenance and cardiomyocyte differentiation of the human embryonic stem cell lines, BG01 and HUES-7
}

\author{
CHRIS DENNING ${ }^{*}, 1$, CINZIA ALLEGRUCCI 1,2, HELEN PRIDDLE ${ }^{1,2}$, MARIA D. BARBADILLO-MUÑOZ1,2, \\ DAVID ANDERSON ${ }^{1}$, TIM SELF $^{3}$, NIGEL M. SMITH $^{2,4}$, C. TONY PARKIN ${ }^{4}$ and LORRAINE E. YOUNG ${ }^{1,2}$ \\ ${ }^{1}$ Institute of Genetics, ${ }^{2}$ Division of Obstetrics and Gynaecology and ${ }^{3}$ Institute of Cell Signalling, University of Nottingham, Queens Medical \\ Centre, Nottingham, U.K. and ${ }^{4}$ Department of Cytogenetics, Centre for Medical Genetics, Nottingham City Hospital, Nottingham, U.K.
}

\begin{abstract}
Development of generic differentiation protocols that function in a range of independently-derived human embryonic stem cell (hESC) lines remains challenging due to considerable diversity in culture methods practiced between lines. Maintenance of BG01 and HUES-7 has routinely been on mouse embryonic fibroblast (MEF) feeder layers using manual- and trypsinpassaging, respectively. We adapted both lines to trypsin-passaging on feeders or on Matrigel in feeder-free conditions and assessed proliferation and cardiac differentiation. On feeders, undifferentiated proliferation of BG01 and HUES-7 was supported by all three media tested (BG-SK, HUESC and HUES-nL), although incidence of karyotypic instability increased in both lines in BG-SK. On Matrigel, KSR-containing conditioned medium (CM) promoted undifferentiated cell proliferation, while differentiation occurred in CM containing Plasmanate or ES-screened Fetal Bovine Serum (FBS) and in unconditioned medium containing $100 \mathrm{ng} / \mathrm{ml}$ bFGF. Matrigel cultures were advantageous for transfection but detrimental to embryoid body (EB) formation. However, transfer of hESCs from Matrigel back to feeders and culturing to confluence was found to rescue EB formation. EBs formed efficiently when hESCs on feeders were treated with collagenase, harvested by scraping and then cultured in suspension in CM. Subsequent culture in FBS-containing medium produced spontaneously contracting EBs, for which the mean beat rate was $37.2 \pm 2.3$ and $41.1 \pm 3.1$ beats / min for BG01-EBs and HUES-7-EBs, respectively. Derived cardiomyocytes expressed cardiac genes and responded to pharmacological stimulation. Therefore the same culture and differentiation conditions functioned in two independently-derived hESC lines. Similar studies in other lines may facilitate development of universal protocols.
\end{abstract}

KEY WORDS: embryoid body, differentiation, cardiomyocyte, transfection

\section{Introduction}

Human embryonic stem cells (hESCs) potentially offer new routes to study early development, model genetic disorders, screen novel drugs and develop cell-based therapeutics. Realization of these applications would be greatly facilitated both by derivation of a range of hESC lines that represent a cross-section of genetic / haplotype diversity within the human population and by development of generic differentiation protocols that function between lines.

Although current estimates suggest that approximately 200 hESC lines have been derived worldwide (Brimble et al., 2004), only a proportion are readily available to the scientific community and over $70 \%$ of studies have focused on the Wisconsin lines, $\mathrm{H}$ -
1, -7, -9, -13 and -14 (Thomson et al., 1998; reviewed in Allegrucci et al., 2005; Goh et al., 2005). Few reports describe direct comparisons of independently-derived hESC lines (Abeyta et al., 2004; Amit et al., 2004; Bhattacharya et al., 2004), likely a consequence of the labor-intensive nature of maintaining multiple lines that apparently require different culture media, passaging methods, culture substrates and feeder cell types / densities (Thomson etal., 1998; Reubinoff etal., 2000; Hovatta etal., 2003; Mitalipova et al., 2003; Cowan et al., 2004; Stojkovic et al., 2004). Since these varying culture parameters may influence differentiation capacity, it is challenging to extrapolate the broad applicabil-

Abbreviations used in this paper: EB, embryoid body; hESC, human embryonic stem cell; MEF, mouse embryonic fibroblast.

\footnotetext{
*Address correspondence to: Dr. Chris Denning. Institute of Genetics, University of Nottingham, Queens Medical Centre, Nottingham, NG7 2UH, U.K. Fax: +44-0-115-970-9906. e-mail: chris.denning@nottingham.ac.uk
}

$0214-6282 / 2006 / \$ 25.00$

(c) UBC Press

Printed in Spain

www.intjdevbiol.com 
ity of specific differentiation protocols and thus each must be tested empirically. For example, hESC-derived cardiomyocytes have been produced in sufficient numbers to permit characterization by two strategies: by spontaneous differentiation via embryoid bodies (EBs) from collagenase-passaged $\mathrm{H}-1,-7,-9$ and -14 hESCs (Kehat etal., 2001; Xu etal., 2002; He etal., 2003; Reppel et al., 2004; Xue et al., 2005) and by co-culture induced differentiation of manually-passaged HES-2, -3 and -4 colonies with END2 visceral endoderm-like cells (Mummery et al., 2003; Passier et al., 2005). However, the effectiveness of either strategy on other independently-derived hESC lines is unknown.

We reasoned that using common hESC culture conditions would simplify maintenance of multiple lines and may facilitate translation of specific differentiation protocols between lines. Thus we selected BG01 and HUES-7, which were independentlyderived at BresaGen (Mitalipova etal., 2003) and Harvard University (Cowan et al., 2004) using different embryo culture, inner cell mass isolation, hESC culture and hESC passaging methods. Here we report that the same media can support undifferentiated BG01 and HUES-7 proliferation and that cultures of both lines can be trypsin-passaged either on feeder layers or on Matrigel in
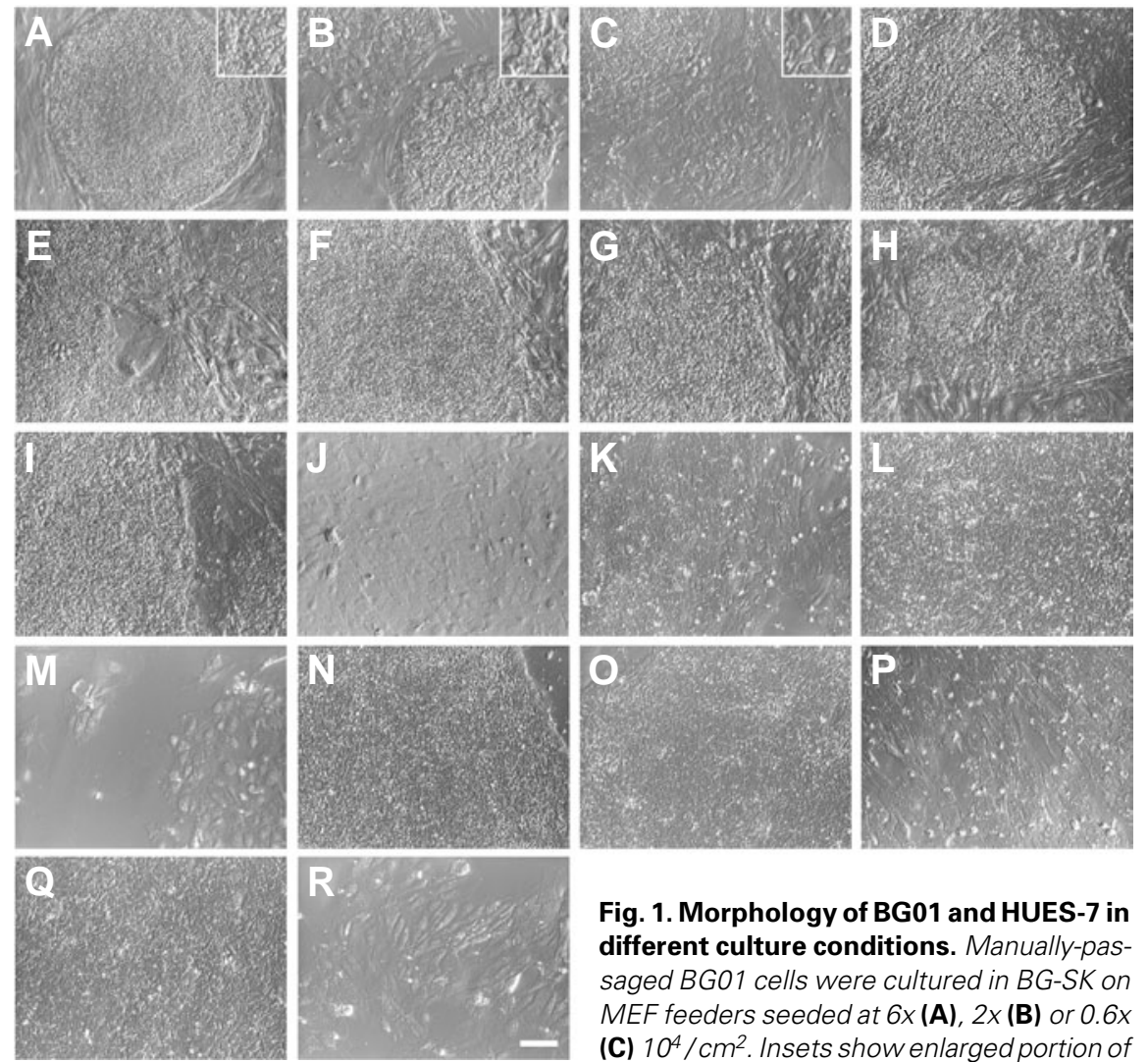

Fig. 1. Morphology of BG01 and HUES-7 in different culture conditions. Manually-passaged BGO1 cells were cultured in BG-SK on MEF feeders seeded at $6 x(\mathbf{A}), 2 x(\mathbf{B})$ or $0.6 x$ (C) $10^{4} / \mathrm{cm}^{2}$. Insets show enlarged portion of the BG01 colonies. Trypsin-passaged BG01

(D, E or F) and HUES-7 (G, H or I) were maintained on feeders seeded at $6 \times 10^{4} \mathrm{cells} / \mathrm{cm}^{2}$ in BG-SK, HUES-C or HUES-nL, respectively. On Matrigel, cultures of BG01 in BG-SK CM (J), HUES-C CM (K) BG-K CM (L) or BG-K-100 (M) passaged with trypsin or in BG-K CM with collagenase (N) are shown. Undifferentiated proliferation of trypsin-passaged BGO1 was supported when the DMEM base of BG-K was replaced with $K O-D M E M(\mathbf{O})$. Proliferation of trypsin-passaged HUES-7 was tested in HUES-C CM (P) BG-K(Q) or BG-K-100 (R). Morphology on Matrigel in HUES-C CM and HUES-nL CM or BG-K-4 and BG-K-100 were similar, thus images for only HUES-C CM and BG-K-100 for each hESC line are shown. Bar, $100 \mu \mathrm{m}$. All brightfield images were taken using Hoffman objective lenses. feeder-free conditions. We demonstrate the utility of Matrigel cultures through transient and stable transfection. Finally, we uate efficiency of EB formation in various conditions and, by that timing of cardiomyocyte differentiation is similar between the

Results

\section{fect of MEF feeder density on BG01 morphology}

First we investigated the morphology of manually-dissected $/ \mathrm{cm}^{2}$, since these densities have been used for culture of $\mathrm{H} 9$ Vallier et al., 2004), all Wisconsin lines $(\mathrm{H}-1,-7,-9,-13$ and -14; tics typically described for undifferentiated hESC cultures, including relatively small size, uniform morphology with the high nuclear to cytoplasmic ratio and surface marker profile of SSEA-1-, 1-61+, TRA-1-81 + (Thomson et al., 1998; Draper et al., 2002) were observed for BG01 cells on 6 $x 10^{4}$ MEFs $/ \mathrm{cm}^{2}$ (Figs. $1 \mathrm{~A}, 2$ ). At higher MEF densities the feeder layer was prone to detaching as a single sheet from the gelatinased plastic, thereby trapping the hESCs. Within 1 passage BG01 cells maintained on MEFs seeded at or less than $2 \times 10^{4} / \mathrm{cm}^{2}$ became enlarged and appeared more differentiated (Fig. 1B,C). Thus, on the basis of these data using BG01 and previous reports using HUES 1-17 (Cowan et al., 2004), we used $6 \times 10^{4}$ MEFs $/ \mathrm{cm}^{2}$ as the standard density both for co-cultures with hESCs and for preparation of MEF conditioned hESC medium (CM) for feeder-free hESC culture.

\section{Common passage method and culture me- dium for BG01 and HUES-7}

Manual dissection is commonly used for propagation of a range of hESC lines, including BG01 (Brimble et al., 2004; Mitalipova et al., 2005). In agreement with these reports, we manually-passaged BG01 52 times in the supplier-recommended medium, which we term BGSK (see Table 1). Most dissected colony pieces attached after passaging and spread out to form colonies of undifferentiated hESCs that were SSEA1-, SSEA4+, TRA-1-60+ and TRA-1-81+ (Figs. 1A, 2). However, the labour-intensiveness of manual passaging prompted us to test the effect of various enzymatic passaging methods and culture media on undifferentiated BG01 and HUES-7 proliferation in feeder-dependent and feeder-free conditions (Table 2).

Passaging of BG01 grown in BG-SK on feeders was not successful with either Collagenase IV $(1 \mathrm{mg} / \mathrm{ml})$ or Dispase $(10 \mathrm{mg} / \mathrm{ml})$. Even with long enzyme incubations (up to $30 \mathrm{~min}$ at $37^{\circ} \mathrm{C}$ ) and scraping or pipetting, BG01 cells did not 


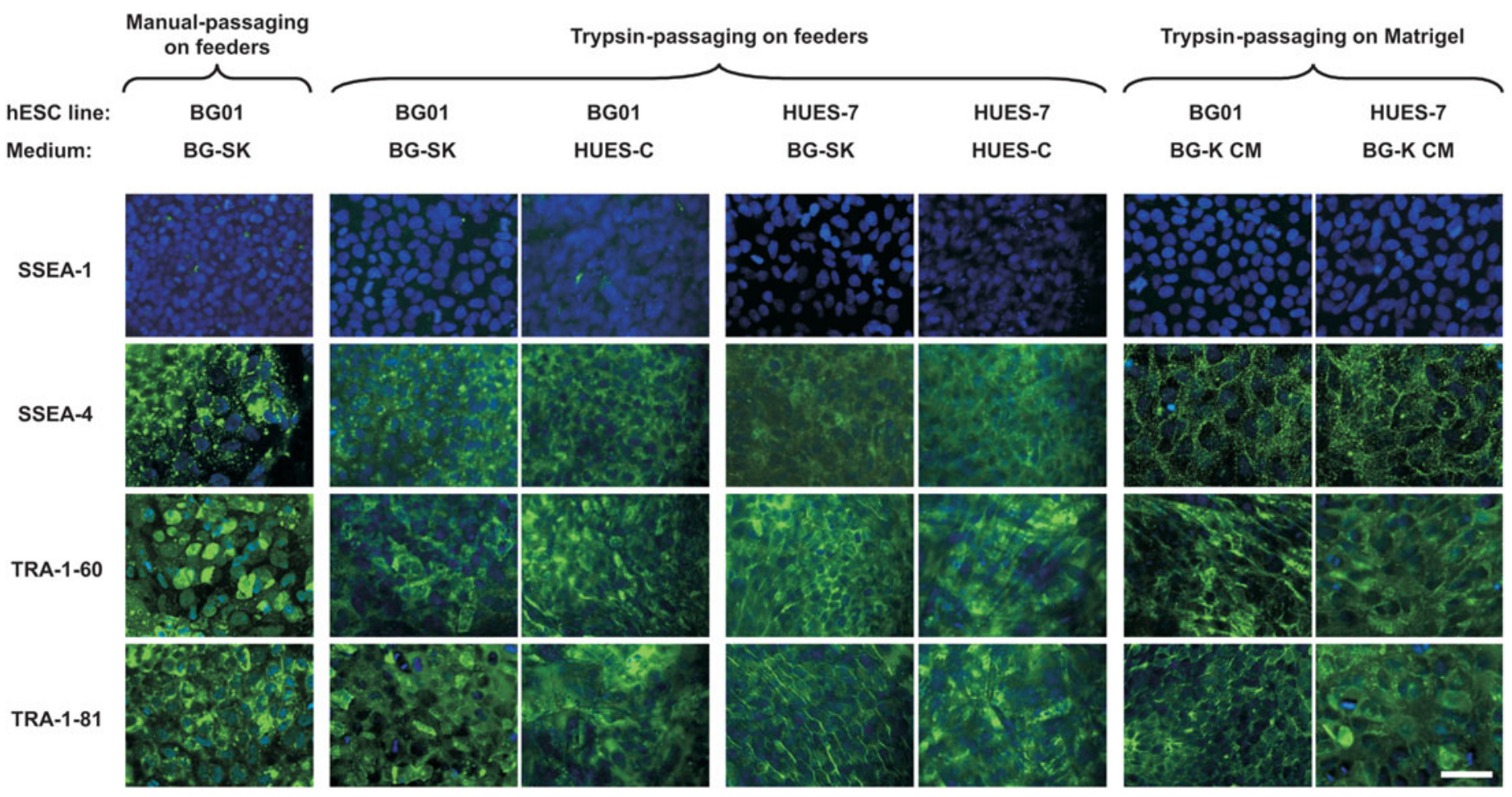

Fig. 2. Surface marker expression. Representative immunofluorescence (green, FITC; blue, DAPI) images are shown for manually-passaged BG01 on feeders in BG-SK, trypsin-passaged BG01 or HUES-7 on feeders in BG-SK or HUES-C and trypsin-passaged BG01 or HUES-7 on Matrigel in BG-K CM. Antibody reactivity of BG01 or HUES-7 on feeders in HUES-C and HUES-nL were indistinguishable, thus images for only HUES-C for each hESC line are shown. Bar, $50 \mu \mathrm{m}$.

detach readily from the MEF feeders. Moreover, most collagenase and dispase-dissociated clusters of BG01 differentiated when transferred to fresh feeders and could not be rescued by further passaging with either enzyme. In contrast, BG01 could be successfully passaged with trypsin (Fig. 1D-F, Table 2), allowing direct comparison with HUES-7, a hESC line adapted to trypsinpassaging soon after derivation (Cowan et al., 2004).

We next attempted to standardize the culture medium. The recommended medium for HUES-7 is HUES-C (see Table 1; Cowan et al., 2004), which differs significantly from BG-SK medium. Duplicate cultures of BG01 and HUES-7 were grown in parallel on feeders for 5 trypsin-passages in BG-SK, HUES-C or HUES-nL (Figs. 13; see Table 1). Interestingly, the morphology of MEFs in HUES-C or HUES-nL was spindle-like with cells starting to retract within 30s of trypsin exposure, whereas, in BG-SK, MEFs were flatter and responded to trypsin only after $>2 \mathrm{~min}$ (data not shown). Nevertheless, over 5 passages, BG01 and HUES-7 cells were phenotypically indistinguishable in the different media with respect to morphology (Fig. 1D-F, G-I) or surface marker expression (Fig. 2). Average population doubling (PD) intervals (Fig. 3A; hours / PD \pm SEM) for BG01 were $80.7 \mathrm{~h} \pm 1.3$ in BG-SK, $85.9 \mathrm{~h} \pm 0.2$ in HUES-C and $91.5 \mathrm{~h} \pm 0.6$ in
HUES-nL. Average PD intervals for HUES-7 were 98.1h \pm 2.2 in BG-SK, 98.5h \pm 0.2 in HUES-C and $106 \mathrm{~h} \pm 0.3$ in HUES-nL (Fig. $3 B$ ). The surprisingly long PD intervals calculated were likely a significant overestimate since substantial debris was observed in the medium after each passage. This indicated high hESC mortality and / or poor attachment post passage, which substantially reduced the theoretical plating densities. Despite similar phenotypic characteristics, genetic differences were observed in the different media. While BG01p50 and HUES-7p25 maintained normal karyotype in HUES-C and HUES-nL during the test period, clonal gains of chromosome $X$ or trisomy 17 (BG01) and $+12+17$

TABLE 1

\section{COMPOSITION OF CULTURE AND DIFFERENTIATION MEDIA TESTED}

\begin{tabular}{lcccccccccccc}
\multicolumn{10}{c}{ Medium } & \multicolumn{10}{c}{ Medium component } \\
\cline { 2 - 4 } & $\begin{array}{c}\text { DMEM- } \\
\text { nam }\end{array}$ & KO & DMEM & ES- & Plas. & KSR & FBS & NEAA & Gln & $\beta-M E$ & bFGF h & LIF \\
BG-SK & $(\%)$ & $(\%)$ & $(\%)$ & $(\%)$ & $(\%)$ & $(\%)$ & $(\%)$ & $(\%)$ & $(\mathrm{mM})$ & $(\mu \mathrm{M})$ & $(\mathrm{ng} / \mathrm{ml})$ & $(\mathrm{ng} / \mathrm{ml})$ \\
BG-K & 78 & - & - & 15 & - & 5 & - & 1 & 2 & 100 & 4 & - \\
BG-K 100 & 83 & - & - & - & - & 15 & & 1 & 2 & 100 & 4 & - \\
HUES-C & - & - & - & - & - & 15 & - & 1 & 2 & 100 & 100 & - \\
HUES-nL & - & 78 & - & - & 10 & 10 & - & 1 & 2 & 55 & 10 & 12 \\
D-FBS & - & - & 78 & - & - & - & 20 & 1 & 2 & 100 & - & - \\
K-FBS & - & 78 & - & - & - & - & 20 & 1 & 2 & 100 & - & - \\
\hline
\end{tabular}

Abbreviations: KO-DMEM, KNOCKOUT-DMEM; ES-FBS, embryonic stem cell screened Fetal Bovine Serum; Plas., Plamanate; KSR, KNOCKOUT Serum Replacement; FBS, Fetal Bovine Serum; $\beta$-ME, $\beta$-mercaptoethanol, bFGF, basic fibroblast growth factor; NEAA, non-essential amino acids; GIn, glutamine; hLIF, human recombinant leukaemia inhibitory factor. 
(HUES-7) were observed in duplicate cultures of the same passage number maintained in BG-SK.

\section{Feeder-free culture and transfection of BG01 and HUES-7}

In initial experiments we found that feeders appeared to confound hESC transfection (data not shown) since we were only able to demonstrate siRNA-induced gene knockdown in BG01 feeder-free cultures. In addition, generation of stable transgenic hESC lines would necessitate feeders resistant to one or more eukaryotic drug selection schemes, ideally requiring access to transgenic mice of the same strain used for feeder derivation. Thus, to simplify and facilitate genetic modification, we investigated proliferation and morphology of feeder-free BG01 and HUES-7 on Matrigel in CM.

Trypsin-passaged BG01 cells cultured in BG-SK CM assumed a differentiated morphology within the first passage on Matrigel (Fig. 1J). Similarly, decreased proliferation rate (Fig. 3C,D) and enlarged cell morphology (Fig. 1K,P) were observed in paralle culture of BG01 and HUES-7 in HUES-C CM or HUES-nL CM. In contrast, parallel cultures of undifferentiated BG01 and HUES7 could be maintained in BG-K CM, which contains $15 \% \mathrm{KSR}$ but no ES-FBS. BG-K CM cultures displayed low mortality after passaging, with $P D$ intervals of $37.9 \pm 0.6$ (BG01) and $29.4 \pm 0.3$ (HUES-7) hours averaged over 7 and 9 passages, respectively (Fig. 3C,D; Table 2). At confluence or high local density, morphology and surface markers were similar to hESCs on feeders (Figs. 1-2). In BG-K CM, BG01 and HUES-7 had a normal karyotype (manuscript in preparation). Unlike BG01 on feeders, BG01 on Matrigel could be passaged with Collagenase IV (Fig. 1N; Table 2 ), although this additionally required scraping to release hESCs from the Matrigel, resulting in substantial cell death following each
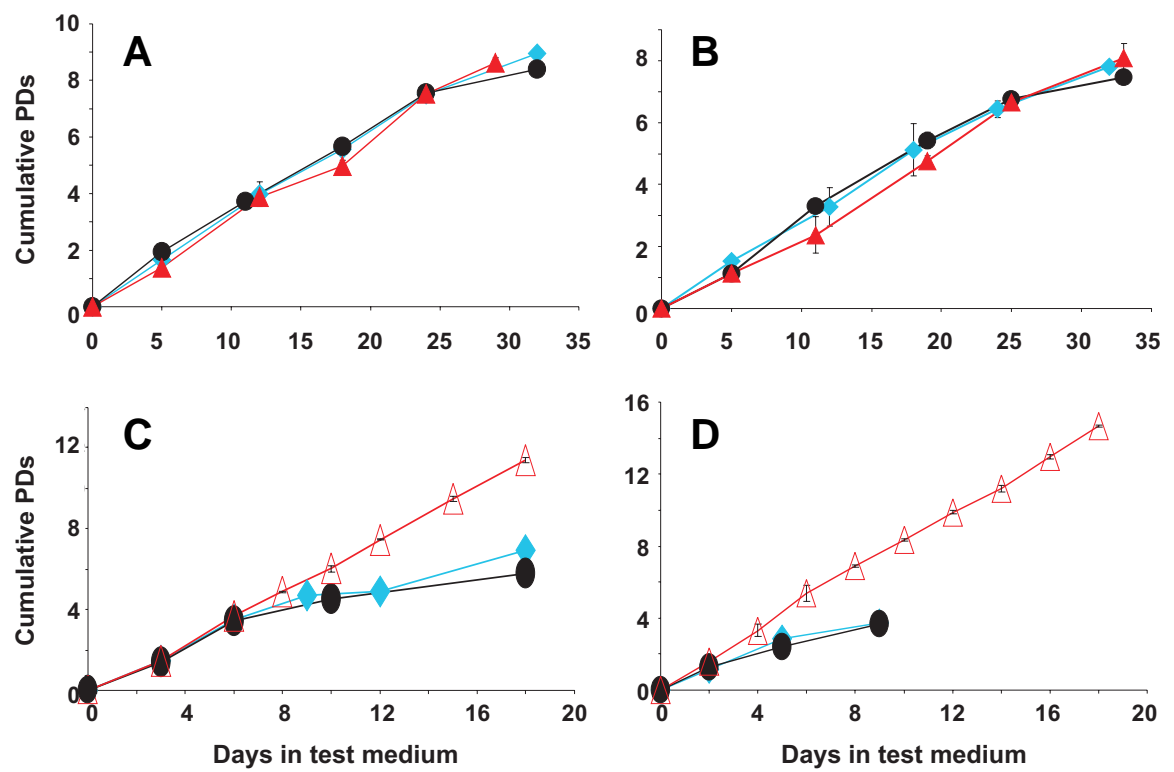

Fig. 3. Growth curves of BG01 and HUES-7. BGO1 and HUES-7 were serially trypsin-passaged on feeders (A,B) or Matrige/ (C,) in different media. BG-SK is represented by solid red triangles; $B G-K$, open red triangles; HUES-C, solid blue diamonds; HUES-nL, solid black circles. CM was used for Matrigel cultures.

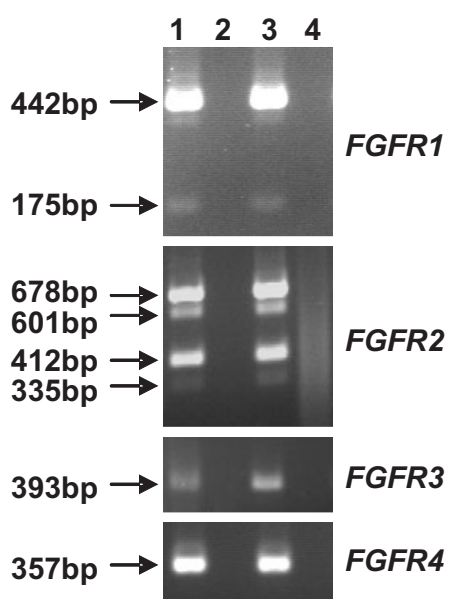

passage, confounding culture expansion.

Recent reports have suggested unconditioned medium containing $40-100 \mathrm{ng} / \mathrm{ml}$ bFGF can support undifferentiated proliferation of the Wisconsin hESC lines H-1, -7, -9 and -14 on Matrigel via BMP signalling pathway inhibition (Xu et al., 2005a; Xu et al., 2005b). Two independent experiments, each using duplicate cultures of both BG01 and HUES-7 set up in parallel, were initiated by seeding up to $14 \times 10^{4}$ trypsin-passaged hESCs $/ \mathrm{cm}^{2}$ in BG-K medium supplemented with bFGF at either $4 \mathrm{ng} / \mathrm{ml}$ or $100 \mathrm{ng} / \mathrm{ml}$ (BG-K-4 or -100 , respectively) and in BG-K CM. Consistent with our observations above, cultures in BG-K CM showed limited mortality post passage and reached confluence in 2-3 days. However, substantial cell death was observed for BG01 and HUES-7 grown in BG-K-4 and -100 and while some of these cultures attained confluency within 3-8 days, they differentiated during the next 1-2 passages (Fig. 1M,R; Table 2). RT-PCR analysis of FGF receptors ( $F G F R$ ) 1-4 in undifferentiated trypsin-passaged BG01 and HUES-7 maintained on Matrigel in BG-K CM revealed expression of all receptors in both lines (Fig. 4).

In contrast to hESCs on feeders, feederfree hESC culture was permissive for transfection. Lipid-mediated transfection of BG01 on Matrigel with short-interfering (si)RNAs directed towards histone deacetylase 1 (HDAC1) or signal transducers and activators of transcription 3 (STAT-3) resulted in knockdown of RNA (by $59 \%$ or $68 \%$, respectively) and protein, as confirmed by Western blot analysis (Fig. 5A,B). Simultaneous transfection with siRNAs to both targets induced knockdown of mRNA (by $44 \%$ HDAC1, $55 \%$ STAT-3, Fig. 5A). In addition, transient delivery of plasmid encoded short-hairpin (sh)RNAs targeted to DNA methyltransferase 1 (DNMTh) to BG01 reduced RNA levels by $\sim 80 \%$ from days $1-3$ after transfection (Fig. $5 \mathrm{C})$. Finally, stable transfection of both BG01 and HUES-7 was effective using a CMVchicken $\beta$-actin promoter to express a green 
fluorescent protein-internal ribosome entry site-puromycin $\mathrm{N}$ acetyltransferase (pcag-gfp-ires-pac) construct (Fig. 5D).

\section{Differentiation via embryoid body formation}

We next assessed whether hESCs from successful culture methods could differentiate via embryoid bodies (EBs). Efficiency of EB formation was scored qualitatively (size) and quantitatively (numbers) after culture of hESCs in suspension for 3-6 days in various media (Fig. 6A; Table 3). Initial experiments with HUES-7 indicated BG-K CM and HUES-C CM were comparable at inducing EB formation (Tables 1 and 3). Efficiency of formation was also comparable in two other media, D-FBS and K-FBS (Table 1), when evaluated on manually-passaged BG01 or trypsin-passaged BG01 and HUES-7 (Table 3). However, with the exception of manually-passaged $B G 01$, where EBs readily formed in all media tested, EB formation efficiency was superior using BG-K CM or HUES-C CM (Table 3). Therefore, for simplicity and standardization, we elected to use BG-K CM for suspension culture.

When BG01 and HUES-7 maintained routinely by trypsin-passaging on feeders were harvested for EBs by using trypsin and then grown in suspension with BG-K CM, 20 small EBs formed per $10^{6} \mathrm{hESCs}$ harvested. Size and numbers ( 50-100 EBs / 106) markedly increased by harvesting trypsin-passaged BG01 and HUES-7 on feeders with collagenase + scraping, hence this method was selected for EB formation (Table 3).

Surprisingly, EB formation from trypsin-passaged BG01 and HUES-7 on Matrigel was poor. We were unable to generate EBs from either hESC line harvested with trypsin and observed only limited formation (0-20 EBs / $10^{6} \mathrm{hESCs}$ ) using collagenase + scraping with BG-K CM (Table 3). However, formation of $\sim 50-100$ well-formed EBs / $10^{6}$ cells was restored by transferring of Matrigel hESCs back to feeder culture (Matrigelłfeeder cultures), growing to confluence and harvesting with collagenase + scraping (Table 3 ), thus providing a simple and effective route to transfect hESCs in feeder-free conditions and yet retain the ability to produce EBs (Fig. 5D).

\section{Cardiomyocyte differentiation from BG01 and HUES-7}

To determine whether a functional cell lineage could be produced from the EBs generated above, we scored the appearance of spontaneously beating outgrowths, which are indicative of cardiomyocyte differentiation. 3-6 day old BG01-EBs and HUES7-EBs were cultured in D-FBS or K-FBS to promote further differentiation. Initial studies indicated D-FBS and K-FBS were comparable for cardiac differentiation and D-FBS was subsequently used (Table 3). Although EBs were cultured in suspension in non-tissue culture treated wells, they appeared to produce matrix and attached to the plastic. Initially they were forced back into suspension by gentle pipetting but after 8 days EBs were left to attach.

Induction of beating EBs was most effective from preparations

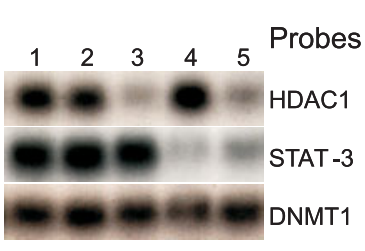

B

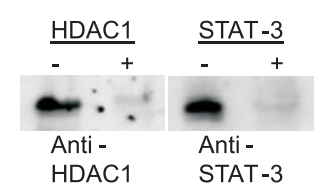

D

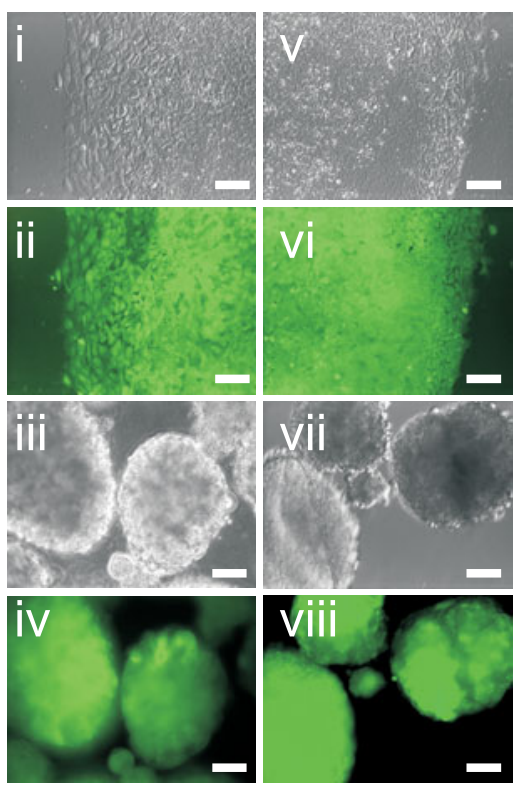

Day after transfection
Fig. 5. Transfection of Matrigel cultures. (A) Northern analysis was carried out 4 days after delivery of HDAC1 and / or STAT-3 siRNAs to BG01. Treatments were with lipofectamine 2000 alone (lane 1) or in lexed with siRNAs: Lane 2, scrambled (lane 3, HDAC1; lane 4, STAT-3; by Western analysis: +, siRNA treated samples; -, control samples. (C) Semi-quantitative mages of BG01 (i-ii) or HUES-7 ( $v$-vi) and derived BG01-EBs (iii and iv) or HUES-7-EBs (viiviii) after stable transfection with a pcag-gfp-ires-pac construct. Bar, $100 \mu \mathrm{m}$. All brightfield mages have been taken using Hoffman objective lenses.

of EBs that had formed efficiently (Table 3). Therefore, we used collagenase to harvest BG01 and HUES-7 cultured on feeders to prepare 1752 BG01-EBs and 3429 HUES-7-EBs (numbers scored at differentiation day 16). Beating was first detected on $\mathrm{d} 13$ in BG01-EBs and on d14 in HUES-7-EBs, while the median day of appearance was d19 for both lines (Fig. 6B). By d36 cumulative totals of 35 (BG01) and 59 (HUES-7) beating EBs were recorded (Fig. 6B). Beating EBs from both lines could still be detected on $\mathrm{d} 50$, the longest time assessed. The cumulative totals represent $2 \%$ (BG01) and 1.7\% (HUES-7) relative to total EBs scored on d16. This is a conservative calculation because total number of EBs consistently decreased during extended culture mostly due to degradation. For example, during one experiment using HUES7 , beating was detected in $21 \mathrm{EBs}$, which represented $7 \%$ relative to total EBs (299) scored on d16 but by d21 the total number of EBs had decreased to only 83 and thus the relative proportion beating increased by $\sim 4$-fold to $25 \%$.

The beat rate of BG01-EBs and HUES-7-EBs derived from cultures on feeders was similar at 37.2 \pm 2.3 (SEM, $n=33$ ) and 41.1 \pm 3.1 (SEM, $n=49)$ beats / $\mathrm{min}$, respectively $(P=0.37)$. Although beating areas were rarely detected for EBs produced directly from 
A
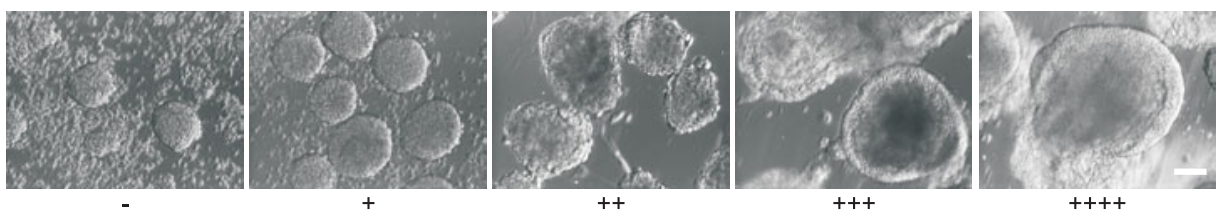

B

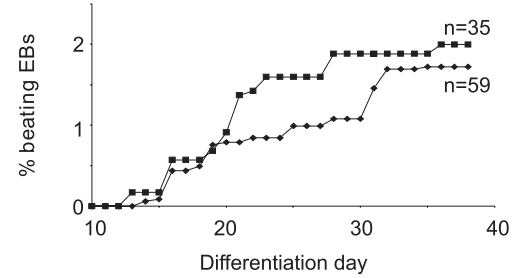

C

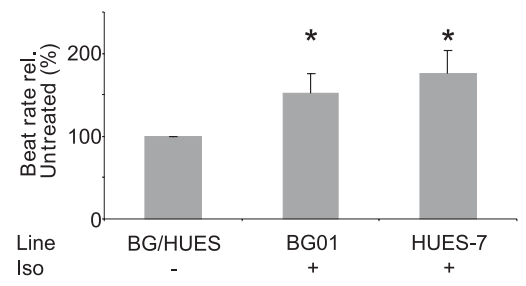

D $\quad \begin{array}{lllll}1 & 2 & 3 & 4 & 5\end{array}$

$\mathbf{E}$

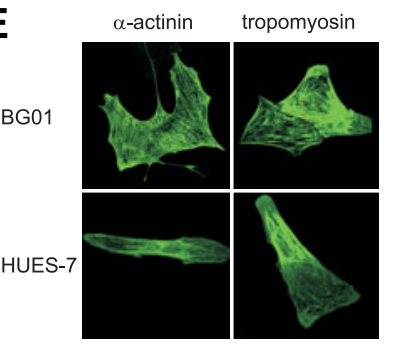

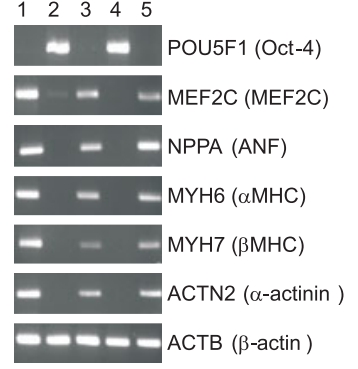

Fig. 6. Embryoid body (EB) and cardiomyocyte formation from BG01 and HUES-7. (A) Representative images of EB size described in the scoring system used in Table 3. Bar, $100 \mu \mathrm{m}$. All brightfield images have been taken using Hoffman objective lenses. (B) Cumulative appearance of 35 beating BG01-EBs (squares) and 59 beating HUES-7-EBs (diamonds) relative to the total number of EBs scored at day 16 (1752 BG01-EBs and 3429 HUES-7-EBS). (C) Response of relative beat rate to $10^{-6} \mathrm{M}$ isoprenaline (Iso), ${ }^{*} P<0.05$. (D) RT-PCR analysis of adult human heart RNA from Ambion (lane 1), undifferentiated BGO1 (lane 2), undifferentiated HUES-7 (lane 4), beating BG01-EB at differentiation day 21 (lane 3) or beating HUES-7-EB at day 37 (lane 5). (E) Antibody reactivity of cells from dissociated beating BG01-EBS and HUES-7-EBS.

Matrigel cultures, beat rates of $30.1 \pm 12.8, \mathrm{n}=4$ (BG01-EBs) and $19.3 \pm 2.4, \mathrm{n}=9$ (HUES-7-EBs) were recorded, which, for HUES-7-EBs, was significantly slower $(P=0.005)$ than beating EBs derived from feeder cultures. Beat rate of EBs derived from hESCs cultured on feeders was significantly increased $(\mathrm{P}<0.05)$ by isoprenaline, a $\beta$-adrenoceptor agonist, to $152 \pm 24 \%$ (SEM; $\mathrm{n}=4)$ and $175 \% \pm 29 \%(\mathrm{n}=5)$ for BG01-EBs and HUES-7-EBs respectively (Fig. 6C).

Gene and protein expression were examined in beating BG01-EBs and HUES-7-EBs. RT-PCR analysis showed high levels of POU5F1 (Oct-4) gene expression levels in undifferentiated BG01 and HUES-7 that were markedly reduced in the beating EBs (Fig. 6D). Genes encoding the cardiac transcription factor, myocyte enhancer factor (MEF2C) and the structural proteins, atrial naturetic factor (ANF), $\alpha$ - and $\beta$-myosin heavy chain (MHC) and $\alpha$-actinin, were all upregulated in beating areas relative to undifferentiated hESCs (Fig. 6D). Antibody staining of cells from dissociated beating BG01-EBs and HUES-7-EBs demonstrated reactivity for tropomyosin and $\alpha$-actinin, revealing sarcomeric striations, albeit disorganised (Fig. 6E).

\section{Discussion}

While there have been considerable efforts to characterize some hESC lines (primarily the Wisconsin lines [reviewed in Allegrucci etal., 2005; Goh etal., 2005; see e.g. Schatten et al., 2005]), for most lines information regarding conditions permissive for culture, transfection and differentiation is lacking. We have provided the following evidence to show culture and differentiation of two independently-derived hESC lines could be standardized: 1) both BG01 and HUES-7 were maintained using trypsin-passaging on $6 \times 10^{4} \mathrm{MEFs} / \mathrm{cm}^{2}$ in HUES-C and HUES-nL or on Matrigel in BG-K CM; 2) EB formation was effective when BG01 and HUES-7 on feeders were harvested by collagenase treatment + scraping and then cultured in suspension in BG-K CM; 3) cardiomyocyte differentiation was induced in BG01-EBs and HUES7 -EBs by extended culture in D-FBS.

Since MEF feeders support undifferentiated hESCs by providing growth substrate and unknown growth factors, feeder density may be a critical parameter. Notably while most hESC lines have been cultured on confluent feeder layers seeded at $\geq 6 \times 10^{4}$ cells $/ \mathrm{cm}^{2}$ (Reubinoff et al., 2000; Mitalipova et al., 2003; Cowan et al., 2004; Stojkovic etal., 2004), undifferentiated proliferation of Wisconsin lines was supported by at 0.6-2 $\times 10^{4} \mathrm{MEFs} / \mathrm{cm}^{2}$ (Thomson et al., 1998; Vallier et al., 2004; Schatten et al., 2005) but densities of $>2 \times 10^{4}$ MEFs / $\mathrm{cm}^{2}$ were detrimental (Heng et al., 2004a). We found $6 \times 10^{4} \mathrm{MEFs} / \mathrm{cm}^{2}$ were required to efficiently support BG01, with differentiated morphology evident at lower densities and peeling of the co-cultures from the plates at higher densities. This is consistent with a report by Zeng et al. (2004) who demonstrated maintenance of BG01 on $10 \times 10^{4}$ and not $1 \times 10^{4} \mathrm{MEFs} / \mathrm{cm}^{2}$ but contrasts with Brimble et al. (2004), where undifferentiated BG01 were maintained by $2 \times 10^{4}$ MEFs / $\mathrm{cm}^{2}$. Since we used the same strain of mouse to derive MEFs as Brimble et al. (2004), these differences are likely explained by variation in media; BG01 was isolated in medium containing $20 \%$ FBS and LIF (Mitalipova et al., 2003) and early cultures were maintained in BG-SK medium (originally recommended to us by BresaGen; used here for feeder density trials and used by Zeng et al. [2004]), whereas Brimble et al. (2004) suggested that BGK CM (containing $20 \% \mathrm{KSR}$ ) minimized differentiation of BG01 cultured on feeders (see also:

ht t p://stemcells.nih.gov/research/protocols/ BresaGen_hESC_manual_2.1.pdf).

Although we found manual dissection of BG01 was successful, we adapted this line to trypsin-passaging on feeders and on Matrigel to facilitate comparison with an independently-derived line, HUES-7 (Cowan et al., 2004). On feeders, proliferation rates 
and morphology were similar between BG01 and HUES-7 in three different media. LIF was not advantageous, consistent with observations in HES-1 and HES-2 (Reubinoff et al., 2000) and H-1, -7 and -9 (Ginis etal., 2004). However, our calculated PD intervals for BG01 and HUES-7 on feeders were $~ 80-100$ hours, significantly longer than previously reported for HUES-7 (48hrs; Cowan et al., 2004) or H-9 and clonal derivatives (35.3hrs; Amit et al., 2004) on feeders. Substantial cell death and / or poor attachment was observed in BG01 and HUES-7 post passage, possibly confounded by incomplete separation of hESCs and high density feeders. Cowan et al. (2004) calculated PD interval by counting HUES-7 periodically over 7 days without passaging, while Amit et al. (2004) achieved efficient separation of $\mathrm{H}-9$ and feeders by exploiting the tolerance of this line to collagenase-passaging on low density MEFs. Furthermore, by transferring BG01 and HUES7 to Matrigel, where post-passage mortality was greatly reduced, we subsequently recorded consistent PD intervals of $\sim 30$ and $\sim 38 \mathrm{hrs}$, respectively, similar to that described by Xu et al. (2001) for collagenase-passaged $\mathrm{H}-1,-7,-9$ and -14 on Matrigel.

We observed a normal karyotype in trypsin-passaged BG01 and HUES-7 on feeders in HUES-C and HUES-nL during the test period, but clonal aneuploid populations were observed in both lines cultured in BG-SK. Interestingly, a recent report attributed karyotypic instability of BG01 cultured in BG-SK medium (albeit supplemented with LIF) to the bulk passaging methods, which employed Cell Dissociation Buffer (CDB) or combined collagenase / trypsin treatment (Mitalipova et al., 2005). However, our data suggest the culture medium may provide an alternative or additional route for instability, which will be an important consideration for future studies.

Of various conditions trialed on Matrigel, only BG-K CM sustained undifferentiated BG01 and HUES-7 proliferation. Since BG01 also maintained undifferentiated morphology when the DMEM base of BG-K was replaced with KO-DMEM (Fig. 1O), it is likely that components within ES-FBS or Plasmanate used to supplement BG-SK or HUES-C and HUES-nL can induce differentiation on Matrigel. We also found that unconditioned BG-K supplemented with $100 \mathrm{ng} / \mathrm{ml}$ of bFGF (FGF-2) did not support BG01 and HUES-7. This contrasts with recent reports where 40$100 \mathrm{ng} / \mathrm{ml}$ bFGF supported $\mathrm{H}-1,-7,-9$ and -14 (Xu et al., 2005a; Xu et al., 2005b). The observed differences may relate to supplier of bFGF (Sigma vs Invitrogen) or passaging method (trypsin vs collagenase), a variable recently demonstrated to quantitatively influence the relative expression of FGFR1-4 (Dvorak et al., 2005). Nevertheless, in the current study, all four receptors were expressed in both BG01 and HUES-7, suggesting the ability to respond to high concentrations of bFGF was not the limiting factor. Thus other genetic or epigenetic causes may be implicated, highlighting the importance of testing protocols on independently-derived lines.

Transfection using lipofection was successful when BG01 and HUES-7 were cultured on Matrigel but not on feeders, possibly suggesting that high density feeders sequester the transfection reagents. Consistent with this suggestion, $\mathrm{H}-7,-9$ and -14 have been successful transfected on feeders when the hESC:feeder ratio was $\sim: 1$ (Matin et al., 2004; Vallier et al., 2004), whereas in our BG01 transfections it was 1:4. Others have temporarily avoided the feeder layer by transducing hESCs in suspension with recombinant lentivirus (Pfeifer et al., 2002; Gropp et al.,
2003] but the necessity of drug resistant feeders for stable selection of hESCs remains (Vallier et al., 2004).

Interestingly, we observed poor EB formation of BG01 and HUES-7 harvested directly from Matrigel, although this could be rescued by short-term transfer back to feeders. This implies expression of key adhesion factors is absent or altered when trypsin-passaged BG01 and HUES-7 are cultured on Matrigel and warrants further investigation. Consistent with this suggestion, the Wisconsin line, $\mathrm{H1}$, has been shown to express high levels of the gap junction protein, connexin 43 and adhesion molecules such as integrins $\alpha 6$ and $\beta 1$ (with moderate levels of $\alpha 2$ and low levels of $\alpha 1, \alpha 2, \alpha 3$ and $\beta 4$ ) in feeder-dependent and feeder-free conditions (Xu et al., 2001), whereas a recent study showed only connexin 43 and integrin $\beta 5$ were highly expressed in BG01 cells on feeders (Zeng et al., 2004). Further analysis is required to determine whether differences in adhesion protein gene expression relate to why Wisconsin lines formed EBs efficiently in KODMEM containing 20\% FBS when directly collagenase-harvested from Matrigel (Xu et al., 2001) whereas similar harvesting conditions were not effective in BG01 and HUES-7.

Differentiation of BG01 and HUES-7 resulted in appearance of beating areas between days 13 and 36 , with spontaneous contraction continuing to d50 in some BG01-EBs and HUES-7-EBs. Since derived cardiomyocytes also responded to isoprenaline, expression of $\beta 1$-adrenoceptors is inferred. Analysis by RT-PCR and / or immunocytochemical also demonstrated expression of

TABLE 2

\section{CULTURE METHODS TESTED FOR BG01 AND HUES-7}

\begin{tabular}{|c|c|c|c|}
\hline Culture substrate & Passage method & $\begin{array}{l}\text { Culture medium } \\
\text { (from/to) }\end{array}$ & No. passages tested \\
\hline \multicolumn{4}{|l|}{ BG01 } \\
\hline \multirow[t]{6}{*}{ Feeders } & Manual dissection & BG-SK & 52 (p24 to p76) \\
\hline & Collagenase & BG-SK & $\mathrm{D}$ \\
\hline & Dispase & BG-SK & D \\
\hline & Trypsin & BG-SK & $14(p 36$ to $p 50){ }^{*} \mathrm{~K}$ \\
\hline & & HUES-C & 5 (p45 to $p 50)$ * \\
\hline & & HUES-nL & $5(p 45$ to $p 50) *$ \\
\hline \multirow[t]{9}{*}{ Matrigel } & Collagenase & BG-K CM & 28 (p41 to p69) \\
\hline & Trypsin & BG-K CM & $10(\mathrm{p} 42$ to $\mathrm{p} 52){ }^{*}$ \\
\hline & & & 25 (p39 to p64) \\
\hline & & BG-SK CM & $\mathrm{D}$ \\
\hline & & HUES-C CM & 5 (p42 to $p 47){ }^{*} D$ \\
\hline & & HUES-nL CM & $4(p 42$ to $p 46){ }^{*} D$ \\
\hline & & BG-K-4 & 2 (p48 to $p 50) D$ \\
\hline & & BG-K-100 & 2 (p45 to $p 47$ ) D \\
\hline & & & 2 (p48 to $p 50) D$ \\
\hline \multicolumn{4}{|l|}{ HUES-7 } \\
\hline \multirow[t]{3}{*}{ Feeders } & Trypsin & BG-SK & 5 (p20 to $p 25)^{*} \mathrm{~K}$ \\
\hline & & HUES-C & 13 (p12 to $p 25)^{*}$ \\
\hline & & HUES-nL & 5 (p20 to p25) * \\
\hline \multirow[t]{6}{*}{ Matrigel } & Trypsin & BG-K CM & $14(\mathrm{p} 23 \text { to } \mathrm{p} 37)^{*}$ \\
\hline & & HUES-C CM & 3 (p23 to $p 26){ }^{*} D$ \\
\hline & & HUES-nL CM & 3 (p23 to $p 26){ }^{*} D$ \\
\hline & & BG-K-4 & 2 (p31 to $p 33$ ) D \\
\hline & & BG-K-100 & 2 (p27 to $p 30) D$ \\
\hline & & & 2 (p31 to p33) D \\
\hline
\end{tabular}

* denotes samples featured in growth curves in Fig. 3. Also indicated are: D, sample differentiated; $\mathrm{K}$, high proportion of cells with abnormal karyotype: $+\mathrm{X}$ or +17 (BG01) and $+12+17$ (HUES-7). 
cardiac transcription factors and structural proteins. These observations are consistent with those of others using HES-2 (Mummery et al., 2003) and $\mathrm{H}-1,-7,-9$ and -14 (Kehat et al., 2001; Xu et al., 2002; He et al., 2003; Reppel et al., 2004; Xue et al., 2005). However, unlike these reports where relatively high numbers of beating outgrowths (8-70\%) were identified, the relative proportion of beating BG01-EBs and HUES-7-EBs ranged from $2 \%$ (relative to total EBs counted early in differentiation) to $~ 8 \%$ (relative to total EBs counted later in differentiation). While differences may relate to variation in passaging method and / or genetics between these lines and BG01 or HUES-7, in contrast to these reports, we did not induce cardiac differentiation with batch selected serum (He et al., 2003; Reppel et al., 2004), 5-azadeoxycytidine (Xu et al., 2002) ascorbic acid (Passier et al., 2005) or by co-culture with visceral endoderm-like cells (Passier et al., 2005). These and other cardiac inducers such as growth factors (e.g. members of the TGF-b1 superfamily), oxytocin, erythropoietin and DMSO (Heng et al., 2004b), may facilitate cardiomyogenesis in BG01 and HUES-7.

In conclusion, we have identified standardized conditions for BG01 and HUES-7 culture and differentiation and initiated characterization of derived cardiomyocytes. Thus we routinely maintain undifferentiated BG01 and HUES-7 using trypsin-passaging on Matrigel in BG-K conditioned medium. Efficient formation of embryoid bodies is achieved by transferring hESCs transiently from Matrigel back to feeders before harvesting with collagenase. Further differentiation is achieved by suspension culture in BG-K conditioned medium for 6 days prior to long-term culture in D-

TABLE 3

\section{EFFICIENCY OF EMBRYOID BODY FORMATION FROM BG01 AND HUES-7}

\begin{tabular}{|c|c|c|c|c|c|}
\hline $\begin{array}{l}\text { hESC line \& } \\
\text { culture method }\end{array}$ & Harvesting method & $\begin{array}{c}\text { Medium } 1 \\
\text { (days 3-6 of } \\
\text { differentiation) }\end{array}$ & $\begin{array}{c}\text { Efficiency of EB } \\
\text { formation }^{b}\end{array}$ & $\begin{array}{c}\text { Medium } 2 \\
\text { (continued } \\
\text { differentiation) }\end{array}$ & $\begin{array}{c}\text { Beating } \\
\text { areas } \\
\text { observed }\end{array}$ \\
\hline \multicolumn{6}{|l|}{ BG01 } \\
\hline \multirow[t]{3}{*}{ Manual / feeders } & Manual dissection & D-FBS & ++++ & D-FBS & Yes \\
\hline & & K-FBS & ++++ & K-FBS & Yes \\
\hline & & BG-K CM & ++++ & D-FBS & Yes \\
\hline Trypsin / feeders & Collagenase + scraping & BG-K CM & ++++ & D-FBS & Yes \\
\hline \multirow[t]{3}{*}{ Trypsin / matrigel } & Collagenase + scraping & D-FBS & - & $\mathrm{n} / \mathrm{a}$ & - \\
\hline & & K-FBS & - & $\mathrm{n} / \mathrm{a}$ & - \\
\hline & & BG-K CM & + & D-FBS & Rarely \\
\hline Trypsin $\left(\mathrm{M} \rightarrow \mathrm{F}^{\mathrm{a}}\right)$ & Collagenase + scraping & BG-K CM & ++++ & D-FBS & Yes \\
\hline \multicolumn{6}{|l|}{ HUES-7 } \\
\hline \multirow[t]{3}{*}{ Trypsin / feeders } & Trypsin & D-FBS & ++ & D-FBS & Rarely \\
\hline & & K-FBS & ++ & D-FBS & No \\
\hline & & BG-K CM & +++ & D-FBS & No \\
\hline \multirow[t]{4}{*}{ Trypsin / feeders } & Collagenase + scraping & D-FBS & +++ & D-FBS & Yes \\
\hline & & K-FBS & +++ & D-FBS & Yes \\
\hline & & BG-K CM & ++++ & D-FBS & Yes \\
\hline & & HUES-C CM & +++ & D-FBS & Yes \\
\hline \multirow[t]{3}{*}{ Trypsin / matrigel } & Collagenase + scraping & D-FBS & - & $\mathrm{n} / \mathrm{a}$ & - \\
\hline & & BG-K CM & + & D-FBS & Rarely \\
\hline & & HUES-C CM & + & D-FBS & Rarely \\
\hline \multirow[t]{2}{*}{ Trypsin $\left(\mathrm{M} \rightarrow \mathrm{F}^{\mathrm{a}}\right)$} & Collagenase + scraping & D-FBS & +++ & D-FBS & Yes \\
\hline & & BG-K CM & ++++ & D-FBS & Yes \\
\hline
\end{tabular}

a Matrigel cultures were transferred to feeders and grown to confluence before harvesting for EBs.

${ }^{b}$ Grading system reflects both size and number of EBs. For representative images, see Fig. 5.
FBS. Whether the protocols applied to these two lines with very diverse derivation and culture backgrounds can be further applied to other independently-derived lines should now be tested. Clearly however, standardization in a range of independently-derived hESC lines that recapitulate human genetic diversity will facilitate use of derived, differentiated lineages in drug screening, disease modeling and transplantation.

\section{Materials and Methods}

\section{Materials and general culture}

All culture components were from Invitrogen and all chemicals were from Sigma unless otherwise specified. Culture was carried out at $37^{\circ} \mathrm{C}$ in a humidified atmosphere containing $5 \% \mathrm{CO}_{2}$. Medium was changed daily for hESC culture.

\section{Culture of BG01 and HUES-7}

Manually-passaged BG01 (passage 24; p24) were purchased from BresaGen (Athens, GA; Mitalipova et al., 2003) and HUES-7 (p11) were kindly gifted by Harvard University (Cowan et al., 2004). Successful continued culture was by manual dissection (BG01) or trypsin-passaging (BG01 and HUES-7) on MEFs (strain CD1, 13.5dpc) and by collagenasepassaging (BG01) or trypsin-passaging (BG01 and HUES-7) feeder-free on Matrigel. MEF feeders were cultured in DMEM High Glucose supplemented with $10 \%$ Fetal Bovine Serum (FBS; Invitrogen E.U. Approved), $2 \mathrm{mM}$ glutamine and $1 \%$ non-essential amino acids. MEFs were mitotically inactivated for 2.5 hours with $10 \mu \mathrm{g} / \mathrm{ml}$ mitomycin $\mathrm{C}$, seeded at densities specified in the text and used 24-48h later at p3. Tested media were 1) BG-SK (DMEM-F12 supplemented with 15\% ES-screened Hyclone FBS [ES-FBS], 5\% KNOCKOUT Serum Replacement [KSR], $100 \mu \mathrm{M} \beta-$ mercaptoethanol $[\beta-\mathrm{ME}], 4 \mathrm{ng} / \mathrm{ml}$ basic fibroblast growth factor [bFGF], $1 \%$ non-essential amino acids [NEAA], 2mM glutamine); 2) BG-K (as for BG-SK but supplemented with $15 \% \mathrm{KSR}$ and no FBS); 3) BG-K-100 (as for BG-K but supplemented with $100 \mathrm{ng} / \mathrm{ml}$ bFGF); 4) HUESC (KNOCKOUT DMEM supplemented with $10 \%$ Plasmanate, $10 \% \mathrm{KSR}, 55 \mu \mathrm{M}$ b-ME, $10 \mathrm{ng} / \mathrm{ml}$ bFGF, 12ng/ml leukaemia inhibitory factor (LIF), $1 \%$ NEAA, 2mM glutamine); 5) HUES-nL (as for HUES-C but no LIF). For Matrigel culture, medium was conditioned on mitotically inactivated MEFs for 20-24 hours, harvested and supplemented with $4 \mathrm{ng} / \mathrm{ml}$ (BG-SK, BG-K) or $5 \mathrm{ng} / \mathrm{ml}$ (HUES-C, HUES-nL) bFGF.

For MEF feeder culture, BG01 colonies of $\sim 0.5-1.0 \mathrm{~mm}$ diameter with undifferentiated morphology were manually-dissected into 8 pieces using a Stem Cell ToolTM (Swemed Lab) under a stereomicroscope and seeded onto fresh MEFs. Alternatively BG01 or HUES-7 cultures on feeders were incubated with $0.5 \%$ TrypsinEDTA for $1-2$ min at $37^{\circ} \mathrm{C}$. After disaggregation by pipetting, large clumps of feeders were eliminated by centrifugation at $100 \times \mathrm{g}$ for $6 \mathrm{~s}$. For feeder-free culture on Matrix Growth Factor Reduced Matrigel (BD Biosciences) coated flasks, cells were passaged either by $1 \mathrm{mg} / \mathrm{ml}$ Collagenase IV treatment (BG01) for $3 \mathrm{~min}$ at $37^{\circ} \mathrm{C}$ followed by gentle scraping of the colonies or by $0.05 \%$ Trypsin-EDTA treatment (BG01 and HUES-7) of the cell monolayer for $1 \mathrm{~min}$ at $37^{\circ} \mathrm{C}$.

Population doublings (PDs) at each pas- 
sage were calculated using the formula: $\log 10$ (total cell counts/cells seeded) / Log10 (2). Proliferation rates over a minimum of 5 passages were calculated by hours in test culture/cumulative PDs.

Analysis of FGFR1-4 was carried out by RT-PCR on undifferentiated trypsin-passaged BG01p48 and HUES-7p28 cells maintained on Matrigel in BG-K CM. RT was carried out on extracted RNA (RNAeasy kit, Qiagen) using Superscript II (Invitrogen) according to manufacturer's instructions. PCR cycle parameters were $94^{\circ} \mathrm{C} 15 \mathrm{~min}$ for 1 cycle, $\left[94^{\circ} \mathrm{C} 30 \mathrm{sec}, 60^{\circ} \mathrm{C}\right.$ $30 \mathrm{sec}, 68^{\circ} \mathrm{C} 1 \mathrm{~min}$ for 40 cycles], 68ㅇ $10 \mathrm{~min}$ for 1 cycle using High Fidelity PCR Master Mix (Roche). Primers were designed to map to exons known to be common to all isoforms, as indicated from the NCBI Entrez Gene database (http://www.ncbi.nlm.nih.gov/entrez/query.fcgi?db=gene). FGFR1, Gene ID 2260,

$\mathrm{F}=$ 5'- ATGTGGAGCTGGAAGTGCCTCCT-3' and

R = 5'-GGTTTGGTTTGGTGTTATCTGTTTCTT-3'; FGFR2, Gene ID 2263,

$\mathrm{F}=5^{\prime}$-CTCCTTCAGTTTAGTTGAGGATACCA-3' and

$\mathrm{R}=$ 5'-CCACAACATCCAGGTGGTACGTGT-3';

FGFR3, Gene ID 2261,

$\mathrm{F}=$ 5'-GTCAAGGATGGCACAGGGCTGGT-3' and

$\mathrm{R}=$ 5'-CTTGATGCCTCCAATGCGGTGCT-3';

FGFR4, Gene ID 2264,

$\mathrm{F}=$ 5'-ATGCGGCTGCTGCTGGCCCTGT-3' and

$\mathrm{R}=$ 5'-GTCACCTGTAATCAAGGTGAGATTCT-3'.

\section{Immunocytochemistry}

SSEA-1, SSEA-4, TRA-1-60 and TRA-1-81 surface markers of undifferentiated, paraformaldehyde-fixed hESCs were assessed by permeabilizing cells with Triton-X100 and then blocking with $4 \%$ goats serum in PBS for $30 \mathrm{~min}$. hESCs preparations were incubated with $20 \mu \mathrm{g} /$ $\mathrm{ml}$ of the relevant primary antibody (ES Cell Characterization kit, Chemicon, 1:50) for $1 \mathrm{hr}$ and with $30 \mu \mathrm{g} / \mathrm{ml}$ FITC-conjugated goat anti-mouse IgG+lgM secondary antibody (Jackson Immuno Research Inc, 1:50) for $45 \mathrm{~min}$. For cardiomyocyte characterization, beating EBs were dissociated by treatment with Cell Dissociation Buffer (CDB) for 15 min at $37^{\circ} \mathrm{C}$. Permeablized (Triton-X100), paraformaldehyde-fixed cells were blocked with $4 \%$ goats serum in PBS for $30 \mathrm{~min}$, incubated with mouse antitropomyosin (1:50; Sigma T9283) or anti- $\alpha$-actinin (1:800; Sigma A7811) for $1 \mathrm{hr}$ and then incubated with FITC-conjugated goat anti-mouse IgG for $1 \mathrm{hr}$. hESC marker and cardiomyocyte preparations were mounted by using Vectashield (Vector Laboratories) with or without DAPI respectively and observed under an epifluorescence microscope.

\section{hESC transfection and analysis}

Lipofectamine 2000 was used for hESC transfection. Transient knockdown in BG01 using STAT-3 and / or HDAC1 siRNA or DNMT1 shRNA was achieved by incubating $10 \mu \mathrm{l}$ of $20 \mu \mathrm{M}$ siRNA (STAT-3 and HDAC1 SmartPoolTM; Upstate Biologicals) or $2 \mu \mathrm{g} D N M T 1$ shRNA plasmid (gifted from Matsukura et al. [2003]) with $2 \mu$ Lipofectamine 2000 according to manufacturers instructions (Invitrogen). Complexes were added to $0.15 \times 10^{6}$ BG01 cells in suspension in $2 \mathrm{ml} \mathrm{BG-K-CM}$ and seeded to a $35 \mathrm{~mm}$ Matrigel-coated dish. For northern analysis, $20 \mu \mathrm{g}$ RNA / sample was blotted, crosslinked and then hybridized at $42^{\circ} \mathrm{C}$ in ultrahyb buffer (Ambion) for $16 \mathrm{hrs}$ with STAT-3, HDAC1 or DNMT1 probes, which had been generated by RT-PCR.

STAT-3 primers

$\mathrm{F}=5^{\prime}$-atggcccaatggaatcagctacagc-3' and

$\mathrm{R}=$ 5'-ggtgatcaggtgcagctcctcag-3', Accession NM_139276;

HDAC1 primers

$\mathrm{F}=5^{\prime}$-atggcgcagacgcagggcacc- 3 and

$R=$ 5'-gcaacctaaccgatccccagatag -3', Accession NM_004964; DNMT1 primers

$\mathrm{F}=5^{\prime}$-gtgggggactgtgtctctgt-3' and

$R=5$ '-gaaagctgcatgtcctcaca-3', Accession NM_001379). For RTPCR semi-quantitation of DNMT1, total RNA was extracted using RNAeasy kit, (Qiagen) and RT was carried out using Omniscript (Invitrogen) according to manufacturer's instructions. Multiplex PCR was performed using DNMT1 primers together $18 S$ primers and competimer (2:8 ratio, Ambion). PCR cycle parameters were $94^{\circ} \mathrm{C} 3 \mathrm{~min}$ for 1 cycle, [94을 $1 \mathrm{~min}$, $57^{\circ} \mathrm{C} 1 \mathrm{~min}, 72^{\circ} \mathrm{C} 1 \mathrm{~min}$ for 30 cycles], $72^{\circ} \mathrm{C} 7 \mathrm{~min}$ for 1 cycle using Taq DNA polymerase (Roche). Western blot analysis of STAT-3 and HDAC1 was performed by sample separation (15mg/lane) on $12.5 \%$ SDS PAGE and blotting onto nitrocellulose membrane (PhastSystem, Amesham). Blots were blocked with $2 \%$ BSA blocking reagent in TBST-I (15 mM Tris$\mathrm{HCl}, 150 \mathrm{mM} \mathrm{NaCl}, 0.2 \%$ Tween 20, pH7.5) for $1 \mathrm{hr}$, incubated with $2 \mu \mathrm{g} /$ $\mathrm{ml}$ diluted anti-STAT3 or anti-HDAC1 antibody (Upstate Biologicals) for $16 \mathrm{hrs}$ at $4^{\circ} \mathrm{C}$ and then incubated with $1: 25,000$ diluted donkey anti-rabbit IgG-HRP (Amersham, NA934) for $1 \mathrm{hr}$. Band location was resolved by chemiluminescence (ECL Advance Kit, Amersham).

For stable transfection with pcag-gfp-ires-pac (gifted from Ying et al. [2003]), $0.15 \times 10^{6}$ BG01 or HUES-7 cells were seeded in $35 \mathrm{~mm}$ Matrigelcoated dishes. The next day, $5 \mu \mathrm{g}$ plasmid was complexed with $2 \mu \mathrm{l}$ Lipofectamine 2000 according to manufacturer's instructions and added to BG01 or HUES-7 in 2mls BG-K-CM. After 48 hrs, puromycin selection $(300 \mu \mathrm{g} / \mathrm{ml})$ was initiated.

\section{Cardiomyocyte differentiation and analysis}

Assessment of beat rate (beats / $\mathrm{min}$ ) of single beating BG01-EBs and HUES-7-EBs at rest or stimulated with $10^{-6} \mathrm{M}$ isoprenaline was measured at $37^{\circ} \mathrm{C}$ in D-FBS, which contains $1.8 \mathrm{mM} \mathrm{Ca}^{2+}$ and $5.2 \mathrm{mM} \mathrm{K}^{+}$. RT-PCR analysis was performed on adult human heart RNA, undifferentiated BG01 and HUES-7 and derived beating EBs. RT was carried out on extracted RNA (RNAeasy kit, Qiagen) using Superscript II (Invitrogen) according to manufacturer's instructions. PCR cycle parameters were

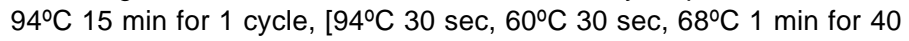
cycles], $68^{\circ} \mathrm{C} 10 \mathrm{~min}$ for 1 cycle using High Fidelity PCR Master Mix (Roche). Primers were:

POUF1 (Oct-4)

$\mathrm{F}=5^{\prime}$-ctatttgggaaggtattcagccaaac- 3 ' and

$\mathrm{R}=$ 5'gaagaacttaatcccaaaaaccctgg-3', Accession BC020712; MEF2C (MEF2C)

$\mathrm{F}=5^{\prime}$-agattacgaggattatggatgaacgt-3'and

$\mathrm{R}=$ 5'-acctgcacttggaggtcgatgtg-3', Accession NM_002397; NPPA (ANF)

$\mathrm{F}=5^{\prime}$ ' ggaaccagaggggagagacagag $-3^{\prime}$ and

$\mathrm{R}=5^{\prime}$-cgccctcagcttgcttttaggag-3', Accession X01471; $M Y H 6(\alpha \mathrm{MHC})$

$\mathrm{F}=5^{\prime}$ - atgaccgatgcccagatggetga -3 ' and

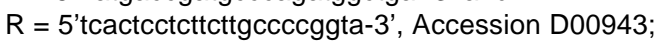

$M Y H 6(\beta M H C)$

$\mathrm{F}=5^{\prime}$ - agctggcccagcggctgcagg $-3^{\prime}$ and

$\mathrm{R}=5^{\prime}$-ctccatcttctcggcctccagct -3 ', Accession X06976;

ACTN2 ( $\alpha$-actinin)

$\mathrm{F}=5^{\prime}$-'ccggcgtgcagtacaactacgtg-3' and

$\mathrm{R}=5$ '-gtagtcaatgaggtcaggccggt-3', Accession $\mathrm{BC} 051770$; ACTN2 ( $\beta$-actin)

$\mathrm{F}=5^{\prime}$-ggacttcgagcaagagatggcca-3' and

$R=5$ '-tcgtcatactcctgcttgctgatc-3', Accession X00351.

\section{Karyotype assessment}

Exponentially growing cultures of at least $1 \times 10^{5}$ cells were treated with $100 \mathrm{ng} / \mathrm{ml}$ colcemid (Karyomax) for $45 \mathrm{~min}$ and harvested (including feeders where used) with $0.05 \%$ Trypsin-EDTA. Pelleted cells ( $200 \mathrm{xg}$ for $4 \mathrm{~min}$ ) were resuspended in $0.6 \%$ sodium citrate and incubated at $37^{\circ} \mathrm{C}$ for $20 \mathrm{~min}$. Cells were then recentrifuged ( $300 \times \mathrm{g}$ for $4 \mathrm{~min}$ ) and fixed by resuspension in $16.7 \%$ glacial acetic acid in methanol and were washed with 2 further changes of fixative. Chromosome spreads were prepared by dropping cells onto glass slides, which were air dried and heated to $70^{\circ} \mathrm{C}$ overnight. Chromosomes were $\mathrm{G}$ banded with trypsin (BD Difco) and stained with Leishmans. For each culture, 30 metaphase spreads 
were examined; full analysis involving band by band comparison between chromosome homologues was performed on 3 spreads and presence of gross abnormalities visually examined in 27 spreads, in accordance with ISCN Human Cytogenetic Nomenclature international guidelines (Mitelman, 1995).

\section{Acknowledgements \\ The authors would like to thank Chad Cowan and Doug Melton for gifting HUES-7. We are grateful to Steve Stice for helpful discussions / training in culture of BGO1 and to Megan Hitchens for providing POU5F1 (Oct-4) primer sequences. This work was funded by MRC and the University of Nottingham.}

\section{References}

ABEYTA, M.J., CLARK, A.T., RODRIGUEZ, R.T., BODNAR, M.S., PERA, R.A. and FIRPO, M.T. (2004). Unique gene expression signatures of independentlyderived human embryonic stem cell lines. Hum Mol Genet. 13: 601-608.

ALLEGRUCCI, C., DENNING, C., STEELE, B., BURRIDGE, P., SINCLAIR, K. and YOUNG, L. (2005). Human Embryonic Stem Cells as a Model for Nutritional Programming: An Evaluation. Reprod Toxicol. 20: 353-367.

AMIT, M., SHARIKI, C., MARGULETS, V. and ITSKOVITZ-ELDOR, J. (2004). Feeder layer- and serum-free culture of human embryonic stem cells. Biol Reprod. 70: 837-845.

BHATTACHARYA, B., MIURA, T., BRANDENBERGER, R., MEJIDO, J., LUO, Y., YANG, A.X., JOSHI, B.H., GINIS, I., THIES, R.S., AMIT, M., LYONS, I., CONDIE, B.G., ITSKOVITZ-ELDOR, J., RAO, M.S. and PURI, R.K. (2004). Gene expression in human embryonic stem cell lines: unique molecular signature. Blood. 103: 2956-2964.

BRIMBLE, S.N., ZENG, X., WEILER, D.A., LUO, Y., LIU, Y., LYONS, I.G., FREED, W.J., ROBINS, A.J., RAO, M.S. and SCHULZ, T.C. (2004). Karyotypic stability, genotyping, differentiation, feeder-free maintenance and gene expression sampling in three human embryonic stem cell lines derived prior to August 9 , 2001. Stem Cells Dev. 13: 585-597.

COWAN, C.A., KLIMANSKAYA, I., MCMAHON, J., ATIENZA, J., WITMYER, J., ZUCKER, J.P., WANG, S., MORTON, C.C., MCMAHON, A.P., POWERS, D. and MELTON, D.A. (2004). Derivation of embryonic stem-cell lines from human blastocysts. N Eng/ J Med. 350: 1353-1356.

DRAPER, J.S., PIGOTT, C., THOMSON, J.A. and ANDREWS, P.W. (2002). Surface antigens of human embryonic stem cells: changes upon differentiation in culture. J Anat. 200: 249-258.

DVORAK, P., DVORAKOVA, D., KOSKOVA, S., VODINSKA, M., NAJVIRTOVA, M., KREKAC, D. and HAMPL, A. (2005). Expression and potential role of fibroblast growth factor 2 and its receptors in human embryonic stem cells. Stem Cells. 23: 1200-1211.

GINIS, I., LUO, Y., MIURA, T., THIES, S., BRANDENBERGER, R., GERECHTNIR, S., AMIT, M., HOKE, A., CARPENTER, M.K., ITSKOVITZ-ELDOR, J. and RAO, M.S. (2004). Differences between human and mouse embryonic stem cells. Dev Biol. 269: 360-380.

GOH, G., SELF, T., BARBADILLO MUÑOZ, M., HALL, I.P., YOUNG, L.E. and DENNING, C. (2005). Molecular and phenotypic analyses of human embryonic stem cell-derived cardiomyocytes: Opportunities and challenges for clinical translation. Thromb Haemost. In press

GROPP, M., ITSYKSON, P., SINGER, O., BEN-HUR, T., REINHARTZ, E., GALUN, E. and REUBINOFF, B.E. (2003). Stable genetic modification of human embryonic stem cells by lentiviral vectors. Mol Ther. 7: 281-287.

HE, J.Q., MA, Y., LEE, Y., THOMSON, J.A. and KAMP, T.J. (2003). Human embryonic stem cells develop into multiple types of cardiac myocytes: action potential characterization. Circ Res 93: 32-39.

HENG, B.C., LIU, H. and CAO, T. (2004a). Feeder cell density-a key parameter in human embryonic stem cell culture. In Vitro Cell Dev Biol Anim. 40: 255-257.

HENG, B.C., HAIDER, H.K.H., SIM, E.K., CAO, T. and NG, S.C. (2004b). Strategies for directing the differentiation of stem cells into the cardiomyogenic lineage in vitro. Cardiovasc Res. 62: 34-42.

HOVATTA, O., MIKKOLA, M., GERTOW, K., STROMBERG, A.M., INZUNZA, J.,
HREINSSON, J., ROZELL, B., BLENNOW, E. ANDANG, M. and AHRLUNDRICHTER, L. (2003). A culture system using human foreskin fibroblasts as feeder cells allows production of human embryonic stem cells. Hum Reprod. 18: 1404-1409.

KEHAT, I., KENYAGIN-KARSENTI, D., SNIR, M., SEGEV, H., AMIT, M., GEPSTEIN, A., LIVNE, E., BINAH, O., ITSKOVITZ-ELDOR, J. and GEPSTEIN, L. (2001). Human embryonic stem cells can differentiate into myocytes with structural and functional properties of cardiomyocytes. J Clin Invest 108: 407-414.

MATIN, M.M., WALSH, J.R., GOKHALE, P.J., DRAPER, J.S., BAHRAMI, A.R., MORTON, I., MOORE, H.D. and ANDREWS, P.W. (2004). Specific knockdown of Oct4 and beta2-microglobulin expression by RNA interference in human embryonic stem cells and embryonic carcinoma cells. Stem Cells. 22: 659-668.

MATSUKURA, S., JONES, P.A. and TAKAI, D. (2003). Establishment of conditional vectors for hairpin siRNA knockdowns-Nucleic Acids Res. 31:e77

MITALIPOVA, M., CALHOUN, J., SHIN, S., WININGER, D., SCHULZ, T., NOGGLE, S., VENABLE, A., LYONS, I., ROBINS, A. and STICE, S. (2003). Human embryonic stem cell lines derived from discarded embryos. Stem Cells. 21:521 526.

MITALIPOVA, M.M., RAO, R.R., HOYER, D.M., JOHNSON, J.A., MEISNER, L.F., JONES, K.L., DALTON, S. and STICE, S.L. (2005). Preserving the genetic integrity of human embryonic stem cells. Nat Biotechnol. 23: 19-20.

MITELMAN F. (1995). ISCN: An International System for Human Cytogenetic Nomenclature, Mitelman F (ed); S. Karger, Basel.

MUMMERY, C., WARD-VAN OOSTWAARD, D., DOEVENDANS, P., SPIJKER, R., VAN DEN BRINK, S., HASSINK, R., VAN DER HEYDEN, M., OPTHOF, T., PERA, M., DE LA RIVIERE, A.B., PASSIER, R. and TERTOOLEN, L. (2003). Differentiation of human embryonic stem cells to cardiomyocytes: role of coculture with visceral endoderm-like cells. Circulation 107: 2733-2740

PASSIER, R., OOSTWAARD, D.W., SNAPPER, J., KLOOTS, J., HASSINK, R.J., KUIJK, E., ROELEN, B., DE LA RIVIERE, A.B. and MUMMERY, C. (2005). Increased cardiomyocyte differentiation from human embryonic stem cells in serum-free cultures. Stem Cel/s 23: 772-780

PFEIFER, A., IKAWA, M., DAYN, Y. and VERMA, I.M. (2002). Transgenesis by lentiviral vectors: lack of gene silencing in mammalian embryonic stem cells and preimplantation embryos. Proc Natl Acad Sci U S A. 99: 2140-2145.

REPPEL, M., BOETTINGER, C. and HESCHELER, J. (2004). Beta-adrenergic and muscarinic modulation of human embryonic stem cell-derived cardiomyocytes. Cell Physiol Biochem. 14: 187-196

REUBINOFF, B.E., PERA, M.F., FONG, C.Y., TROUNSON, A. and BONGSO, A (2000). Embryonic stem cell lines from human blastocysts: somatic differentiation in vitro. Nat Biotechnol. 18: 399-404

SCHATTEN, G., SMITH, J., NAVARA, C., PARK, J.H. and PEDERSEN, R. (2005) Culture of human embryonic stem cells. Nat Methods. 2: 455-463

STOJKOVIC, M., LAKO, M., STRACHAN, T. and MURDOCH, A. (2004). Derivation of human embryonic stem cells from day-8 blastocysts recovered after threestep in vitro culture. Stem Cells. 22: 790-797.

THOMSON, J.A., ITSKOVITZ-ELDOR, J., SHAPIRO, S.S., WAKNITZ, M.A., SWIERGIEL, J.J., MARSHALL, V.S. and JONES, J.M. (1998). Embryonic stem cell lines derived from human blastocysts. Science. 282: 1145-1147

VALLIER, L., RUGG-GUNN, P.J., BOUHON, I.A. ANDERSSON, F.K., SADLER, A.J. and PEDERSEN, R.A. (2004). Enhancing and diminishing gene function in human embryonic stem cells. Stem Cells. 22: 2-11.

XU, C., INOKUMA, M.S., DENHAM, J., GOLDS, K., KUNDU, P., GOLD, J.D. and CARPENTER, M.K. (2001). Feeder-free growth of undifferentiated human embryonic stem cells. Nat Biotechnol. 19: 971-974

XU, C., POLICE, S., RAO, N. and CARPENTER, M.K. (2002). Characterization and enrichment of cardiomyocytes derived from human embryonic stem cells. Circ Res 91: 501-508

XU, C., ROSLER, E., JIANG, J., LEBKOWSKI, J.S., GOLD, J.D., O'SULLIVAN, C., DELAVAN-BOORSMA, K., MOK, M., BRONSTEIN, A. and CARPENTER, M.K (2005b). Basic fibroblast growth factor supports undifferentiated human embryonic stem cell growth without conditioned medium. Stem Cells. 23: 315-323.

XU, R.H., PECK, R.M., LI, D.S., FENG, X., LUDWIG, T. and THOMSON, J.A (2005a). Basic FGF and suppression of BMP signaling sustain undifferentiated proliferation of human ES cells. Nat Methods. 2: 185-190

XUE, T., CHO, H.C., AKAR, F.G., TSANG, S.Y., JONES, S.P., MARBAN, E., 
TOMASELLI, G.F. and LI, R.A. (2005). Functional integration of electrically active cardiac derivatives from genetically engineered human embryonic stem cells with quiescent recipient ventricular cardiomyocytes: insights into the development of cell-based pacemakers. Circulation. 111: 11-20.

YING QL, STAVRIDIS M, GRIFFITHS D, LI M, SMITH A. (2003). Conversion of embryonic stem cells into neuroectodermal precursors in adherent monoculture. Nat Biotechnol. 21:183-6

ZENG, X., MIURA, T., LUO, Y., BHATTACHARYA, B., CONDIE, B., CHEN, J.,
GINIS, I., LYONS, I., MEJIDO, J., PURI, R.K., RAO, M.S. and FREED, W.J. (2004). Properties of pluripotent human embryonic stem cells BG01 and BG02. Stem Cel/s. 22: 292-312.

Received: June 2005 Reviewed by Referees: July 2005 Modified by Authors and Accepted for Publication: October 2005 Edited by: Christine Mummery 